- No. 413: ð. Kakoma 12. April 1880. Lg. tot. 22,$5 ; 12 ; 6,2$. Im Magen unbehaarte Raupen. - No. 387: §. Kakoma 6. April 1881. Lg. 22,$5 ; 12,5 ; 6$. Iris braun. Füsse hornfahl. Schnabel gelb wit horngrauer Spitze. Mundwinkel, Augenring gelb. Nackte Stelle hinter dem Auge gelblich. - No. 333: ð. Kakoma 13. März 1881. Lg. 19,7; 11,2; 5. Iris braun. Füsse blassbräunlichgelb, Nägel von derselben Farbe. Mundwinkel und Augenring hochgelb. Im Magen kleine Gehäuseschnecken.

\title{
Die Brutvögel und Gäste der Umgebung Gronau's in Hannover. Von
}

Adolf Mejer, Lieut. a. D.

Als vor einiger Zeit die ehrenvolle Aufforderung an mich ergangen war, die Brutvögel und Gäste meines Wohngebietes, der Umgebung Gronau's in Hannover, und die darüber gesammelten biologischen Notizen in einer einschlagenden Arbeit aufzuzählen und niederzuschreiben, glaubte ich um so eher dieser Aufforderung nachkommen zu können, als ich seit meiner Kindheit mich der Beobachtung der gefiederten Welt gewidmet hatte und hierdurch sowohl, wie durch sorgfältiges Sammeln von Eiern in meinem Gebiete und Bestimmen der betreftenden Brutvögel, genügend Material für meine Arbeit in Händen zu haben glaubte.

Nach und nach aber wurde es mir klar, welch' schwere Aufgabe ich übernommen hatte und wie sich hier und dort Lücken zeigten, deren Ausfüllung mir einstweilen schwer fallen wird, zumal ich nicht im Stande bin, mein lückenhaftes Wissen von Kennern hiesiger Gegend ergänzen und das, was ich beobachtet, bestätigen lassen zu können. Ich werde jedoch mein Möglichstes aufbieten, um die vorhandenen Lücken mit der Zeit ausfüllen zu können.

Ich glaube daher für meine Arbeit um möglichst schonende Beurtheilung bitten zu dürfen dort, wo solche Lücken sich zeigen, bin aber auch gern bereit und werde es dankbarlichst anerkennen, mir von andern freundlichen Händen diese Lücken ausfüllen helfen $\mathrm{zu}$ lassen.

Mein Beobachtungsgebiet ist zwar nur gering bemessen, denn ich glaubte nur dann recht eingehend die vorkommenden Arten mit Sicherheit constatiren zu können, wenn ich mir ein nicht zu umfangreiches Gebiet wählte. Dieses Gebiet liegt hauptsächlich 
Die Brutvögel u. Gäste der Umgebung Gronau's in Hannover. 369

östlich der Leine nach Hildesheim zu und findet mit den bewaldeten Escherder Bergen und Siebenbergen einerseits und mit der Leine anderseits ungefähr seinen Abschluss. Die Flächenausdehnung mag vielleicht 1-1,5 Quadratmeilen betragen.

Im Osten und Südosten begrenzen mehr oder minder ausgedehnte Waldcomplexe das Gebiet, resp. ist noch ein Theil des Gebietes mit Wäldern bestanden, während die Westhälfte ausschliesslich nur Felder aufzuweisen hat, ausgenommen einige kleine Weidendickichte an den Ufern der Leine. Es fehlen leider dem Gebiete sumpfige oder ausgedehnte Rohr- und Schilfbestände.

Zur besseren Verständlichkeit bemerke ich noch, dass ich mich in der Synonymik sowohl als in der Classification lediglich an unsern Altmeister Brehm halten werde.

So möge denu auch diese Arbeit einen kleinen Beitrag zu der Reihe der Localfaunen auf ornithologischem Gebiete bilden und dazu beitragen, dass man, auf Grund jener Localfaunen, im Stande ist, das Verbreitungsgebiet der einzelnen Vogelarten genau angeben zu können.

1. Cuculus canorus. Der Kukuck ist in unserm Walde nicht selten und bedingungslos anzutreffen; sein Erscheinen fällt ungefähr um die Mitte April und verlässt er uns Ende August bis Anfang September wieder; während seine Ankunft jedem einigermaassen Aufachtenden sofort auffällt, zieht er meist unbemerkt und still von dannen. Es scheint mir, als ob die Anzahl der männlichen Individuen die der weiblichen um ein Bedeutendes übertrifft und daher ist auch die Polygamie des Kukucks leicht zu erklären, wenn man auf den Lockton des $+4-5$ ơ herbeifliegen sieht. Auch der Umstand, dass ich in 15 Jahren nur ein einziges Mal ein Kukucksei gefunden habe, obgleich ich stets eifrig danach gesucht habe und es viele $\delta$ im Gebiet giebt, bestärkt mich in der Annahme, dass es mehr $\delta$ als + giebt. Im Spätsommer trifft man den Kukuck auch weit vom Walde entfernt in Wiesen oder den Baumreihen an Wegen und Gräben folgend an. Durch seinen Ruf trägt er ungemein zur Belebung des Waldes bei und lässt er denselben hören von dem Augenblick seiner Ankunft bis gegen Mitte Juli.

2. Alcedo ispida. Der Eisvogel ist ständiger Brutvogel des Gebietes und hier Winters und Sommers über zu finden. Ihre Nistlöcher legen sie hier an steilen glatten Erdwänden an, bald 
nahe am Wasser, bald entfernt von diesem, immer aber so, dass ein vierbeiniger Räuber nicht in die Höhle gelangen kann. Die Tiefe der sanft ansteigenden Nisthöhlen beträgt ca. 1 Meter und man findet am Ende des Ganges die backofenförmige Erweiterung: von ea. $15 \mathrm{Cm}$. Durchmesser. Gegen Mitte April beginnen die Weibchen unter normalen Verhältnissen mit dem Eierlegen, jedoch findet man auch noch um Mitte Mai frische Eier.

3. Coracias garrula. Die Mandelkrähe wurde in der unmittelbaren Nachbarschaft des Gebietes gelegentlich erlegt und glaube ich deshalb, dieselbe wenigstens als Gast anführen zu dürfen, weiter aber auch erstreckt sich ihr Vorkommen nicht.

4. Caprimulgus europaeus. Der Ziegenmelker ist ein nicht seltener Brutvogel unseres Waldes, welcher gegen Mitte Mai bei uns eintrifft und sein Wohngebiet, den Laubwald in lichten und niedrigen Beständen bezieht. . Abends in der Dämmerung beginnt er sein Leben und zumal in der Fortpflanzungszeit ist er sehr beweglich und unstät. In wundervollem leichten und kaum hörbaren Fluge jagt er nach Náchtschmetterlingen, oder umfliegt er den sich nähernden Menschen, als wolle er sich ihn genau besehen, oder alles Andere, was seine Aufmerksamkeit in Anspruch nimmt, wird von ihm in schönem Fluge umschwärmt. Schon früh, unmittelbar nach Sonnenuntergang lașsen sie in der Paarungszeit ihre Stimme erschallen, das bekannte "Oerrrr" und Errrr", von irgend einem höhern Sitzpunkte aus, oft minutenlang dasselbe anhaltend; dann plötzlich brechen sie ab, wenn sie ihr Weibchen sehen, und verlassen, auf dieses zustreichend, ihren Platz in sonderbarem Fluge, wobei sie mit den Flügeln klatschen und diese dann wieder fast senkrecht erheben und dazu ein sanftes trauliches „krrüit der Gattin zurufen. Im Mai schreiten sie zur Auswahl des Nistplatzes und. gegen Ende dieses Monats findet man ihre 2 Eier, ohne alle Unterlage auf dem Boden, höchstens auf etwas vermodertem Holze, welches sie vorfinden; im Juni findet man die hässlichen schwärzlichen Jungen mit dem Riesenrachen und dicken Kopfe. Bis sie ihre Jungen grossgefüttert haben, scheinen die Nachtschwalben sich ausschliesslich im Walde umherzutreiben, später im Juli und August sieht man sie Abends auch häufig im Felde oder in Gärten nach Nahrung fliegen.

5. Cypselus apus. Der Mauersegler, einer unserer gewandtesten Flieger, ist im Gebiet ständiger Brutvogel, welcher ziemlich häufig auftritt. Er erscheint mit dem Monat Mai und 
verweilt bis in die erste Hälfte des August. Unter dem Dache meines Wohnhauses brüten wenigstens 30-40 Pärchen und umschwärmen während und vor der Brutzeit beständig das Haus oder tummeln sich in unmittelbarer Nähe umher. Sobald aber die Jungen flügge sind und sich selbst ernähren können, unternehmen sie den ganzen Tag über weite Streifzüge, so dass ich schon um Ende Juli glaubte, die Segler seien fortgezogen. Aber allabendlich kamen gegen Sonnenuntergang die Segler zurück, bald einzeln, bald in Gesellschaften, um die Nacht unter dem Dache zuzubringen und am andern Tage wieder zu verschwinden. Und dass es stets dieselben waren, die zurückkamen, beweisst, dass sie gewisse Löcher unter den Dachziegeln allabendlich wieder besetzten. Dieses Umherschweifen tagsüber währete bis etwa zum 13. August, an welchem Abend keine einzige zurückkehrte. Anfang Juni findet man ihre 2-3 Eier in einem aus Strohhalmen, Grasblättern, Federn und Zeugläppchen mittelst eignen Speichels zusammengeklebten Neste, nach 14 tägigem Brüten schlüpfen die Jungen aus.

6. Picus viridis. Der Grünspecht zählt zu den Brutvögeln des Gebietes, kommt an geeigneten Oertlichkeiten nicht selten vor und hält dort das ganze Jahr über aus, unter regelmässigem Verlauf der Dinge. Eine Nisthöhle von ihm zu untersuchen hatte ich noch nicht Gelegenheit, obgleich ich öfter den Vogel brütend angetroffen habe; demzufolge legt er Ende April oder zu Anfang Mai seine 5-7 Eier.

7. Picus canus. Der Grauspecht ist als ein seltener Gast zu verzeichnen; ob er Brutvogel ist, weiss ich nicht mit Bestimmtheit anzugeben, da ich das einzige Exemplar im Winter beobachtet habe, und zur Brütezeit er mir noch nicht wissentlich zu Gesicht gekommen ist. Ich beschränke mich daher einstweilen darauf, ihn als Gast anzusehen.

8. Picus major. Der grosse Buntspecht ist diejenige Spechtart, welche am häufigsten hier vorkommt. Er zählt zu den ständigen Brutvögeln, welche Winter und Sommer das einmal erwählte Gebiet behaupten. Wo er passende Nisthöhlen vorfindet oder sich zimmern kann, siedelt er. sich an, sowohl in Parkanlagen als auch in Wäldern oder grösseren Obstgärten. In der ersten Hälfte des Mai findet man sein aus 5-7 Eiern bestehendes vollzähliges Gelege, welches 14 Tage bebrütet wird.

9. Picus minor. Der kleine Buntspecht ist wohl nur ein äusserst seltener Gast, der nicht im Gebiet brütet, denn nur ein 
einziges Mal habe ich sein Vorkommen zu verzeichnen und zwar im Juli 1878. Es ist mir auch sonst nichts über sein Vorkommen hier berichtet.

10. Iunx (Iynx) torquilla. Der Wendehals ist ein häufiger Brutvogel im Gebiet. Ende April stellt er sich bei uns ein und verlässt uns im August oder September. Er siedelt sich überall in Obstgärten und im Felde an, wo er die passenden Nistböhlen vorfindet; im Walde selbst habe ich ihn meines Wissens noch niemals angetroffen, wohl aber dicht am Waldrande brütend. Um Mitte Mai findet man sein Gelege vollzählig in einem Astloche, welches von dem Vogel benutzt wird, wie er es vorfindet; die Eier liegen höchstens auf etwas Moder; die Bebrütung währt 12 bis 14 Tage.

11. Falco peregrinus. Allwinterlich erscheint mit den grössern Entenflügen, welche von den Seeküsten her sich hier an der Leine einstellen, der Wanderfalke, hält sich den Winter über hier auf und verschwindet mit dem Frühjahr wieder. Es ist mir kein Fall bekannt, dass der Wanderfalk im Gebiet oder dessen unmittelbaren Nachbarschaft gehorstet hätte.

12. Falco subbuteo. Der Lerchenfalk ist von mir öfters während des ganzen Sommers beobachtet, jedoch habe ich keine sicher verbürgte Nachricht, dass dieser Vogel im Gebiet, oder dessen Nachbarschaft gehorstet hätte; möglich ist es allerdings. Ich beobachtete ihn vom Mai bis September.

13. Falcotinnunculus. Der Thurmfalke ist der häufigste Raubvogel des Gebietes nach dem Bussard; so brüteten beispielsweise im Frühjahr 1882 an den Ufern der Leine in hohen Weidenbäumen nicht weniger als 5 Pärchen auf einer Längenausdehnung von ca. 7 Kilometer. In milden Wintern bleibt wohl das eine oder andere Pärchen zum Ueberwintern zurück. Die Mehrzahl jedoch verlässt uns schon zeitig im Herbst und kommt im April wieder zurück. Einige der Horste habe ich selbst erstiegen und fand jedesmal, dass ein altes Krähennest benutzt war; ausserdem fand sich in den Horsten jedesmal etwas Flusssand von Linsenund Erbsendicke vor; ob dieses von dem Vogel eingetragen, vermag ich nicht zu sagen. Das erste Ei fand ich am 3. Mai, es wurde aber nicht mehr zu diesem Ei hinzugelegt, so dass ich nach etwa 8 Tagen dasselbe aushob. Gegen den 20. Mai fand ich bei allen Horsten die Weibchen brütend, nur in einem Horst hatte das Weibchen noch nicht ausgelegt. Bei dem geschossenen Vogel 
Die Brutvögel u. Gäste der Umgebung Gronau's in Hannover. 373

fand ich ein fast völlig ausgebildetes Ei im Schlauch vor, welches zum Theil mit der harten Kalkschaale umgeben war; letztere, obwohl noch ganz dünn und biegsam, trug schon die Anfänge der Eifärbung. Die Brütezeit fällt also in die zweite Hälfte des Monats Mai.

14. Astur palumbarius. Der Hühnerhabicht gehört zu den regelmässigen Brutvögeln des Gebietes; jedoch ist er glücklicherweise selten. Ich kenne mehrere Horste, welche regelmässig mehrere Jahre hintereinander von einem Pärchen besetzt wurden, obgleich in jedem Frühjahr das Weibchen am Horst erlegt wurde. Das Pärchen tummelt sich schon lange vor Beginn der Fortpflanzung in der Nähe seiner erwählten Horstplätze umher und verräth dadurch bald diesen, so dass es im Ganzen ziemlich leicht fällt, die Gegend auszukundschaften, in welcher ein Paar nisten wird; alsdann kann es auch nicht mehr schwer fallen, den Horst selbst zu finden, da die Alten sehr viel und laut in der Nähe des Horstes schreien. Die Legezeit fällt meist um die Mitte des Monats April. Ich selbst habe manch liebes Mal einen Hühnerhabichts-Horst erstiegen, aber nie vor Mitte April das volle Gelege gefunden; dieses besteht aus $3-4$ Eiern, von gewöhnlich einfarbiger blassgrüner Farbe.

15. Astur nisus. Der Sperber ist ebenfalls Brutvogel im Gebiet und ist Winters und Sommers zu jeder Zeit zu beobachten. Seinen Horst findet man jedoch meist in dichten Beständen und nicht sehr hoch, während der Hühnerhabicht mehr den Hochwald vorzieht. Die Legezeit scheint nicht ganz genau bei allen Vögeln übereinzustimmen, denn man kann von Mitte Mai bis zu Anfang Juni frische Gelege finden. Einst sah ich einen Sperber auf seinem Raubzuge an das Nest einer Hirundo urbica fliegen und aus demselben einen lautschreienden Spatzen mit einem seiner Fänge herausziehen; dieser Sperling war beim Herankommen des Sperbers in das Nest gekrochen, um dort Schutz zu suchen, und sich wohl ganz sicher dünkend, liess er beständig seinen Warnungsruf erschallen, bis die langen Krallen des Sperbers Allem ein Ende machten.

16. Haliaëtus albicilla. Wenn ich einen grossen Raubvogel, den ich in diesem Herbste (1882) über dem überschwemmten Ufer der Leine eine längere Zeit schweben sah, für einen Seeadler anspreche, so glaube ich den gesehenen Vogel richtig zu bezeichnen. Ich konnte ihn leider nicht erlegen, aber so nahe habe ich ihn 
gesehen, dass eine Täuschung über die Familie der Aquilinae nicht gut möglich war. Ein Steinadler wird es nicht gewesen sein, da dieselben sehr viel seltener sind, als der Seeadler.

17. Pandion haliaëtus. Der Flussadler gehört zu den unser Gebiet nicht regelmässig besuchenden Gästen; bisweilen habe ich Gelegenheit gefunden, ihn auf seinen Herbstwanderungen, wobei er sich immer einige Tage am Flusse aufhielt und auch die Fischteiche der Nachbarschaft besuchte, zu beobachten, so zum letzten Male im October 1880.

18. Milvus regalis. Der rothe Milan zählt zu unsern regelmässigen Brutvögeln; im Frühjahr stellt er sich im März ein und bezieht sein altes Wohngebiet wieder. Im Herbst sieht man den fortziehenden Milan oft bis in den November hinein hier verweilen und erst die rauhe Witterung vertreibt inn; auf seinen Herbstwanderungen habe ich schon Gesellschaften von 20 Stiick vereint gesehen. Im Allgemeinen ist der Milan aber seltener als der Bussard und als Brutvogel nur in wenigen Pärchen vorhanden. Sein Fortpflanzungsgeschäft beginnt mit dem Monat April; er bessert einen passenden, vorgefundenen Horst aus und verwendet die wunderbarsten Gegenstände zur Ausschmückung seiner Burg. Von Mitte April an findet man das volle Gelege, welches aus 2 bis 3 Eiern besteht.

19. Circus cyareus. Die Kornweihe ist heute noch Brutvogel im Gebiet, hat aber in den letzten 10 Jahren bedeutend abgenommen; zu Anfang der 70 er Jahre sah man allsommerlich noch mehrere Pärchen, heute kaum noch eins. Im Mai bezieht sie ihr altes Wohngebiet und verweilt bis Ende September oder Anfang October. Sie nistet in Kornfeldern auf der Erde und legt 3-4 Eier.

20. Pernis apivorus. Der Wespenbussard gehört auch $\mathrm{zu}$ den Brutrögeln des Gebietes, jedoch fühle ich mich noch nicht berechtigt, denselben, als regelmässigen Brutvogel $\mathrm{zu}$ bezeichnen, da ich seinen Horst erst einmal, im Jahre 1881, gefunden habe und andere Fälle mir nicht bekannt geworden sind. Dieser Horst stand in einer Eiche und war sehr flach; die ca. 12-15 Centimeter tiefe Mulde war mit frischem und bereits vertrocknetem Buchenlaub ausgelegt. Am 28. Mai lag das erste Ei im Horst und am 3. oder 4. Juni (am 2. Juni lag noch immer ein Ei im Horst) wurde das zweite Ei zugelegt. Ueber Ankunft und Abzug vermag ich keine Auskunft zu geben. 
Die Brutvögel u. Gäste der Umgegend Gronau's in Hannover. 375

21. Buteo vulgaris. Der Mäusebussard ist unser gemeinster hier brütende Raubvogel; auch die weisse Varietät ist nicht selten. Ueber den Winteraufenthalt des Bussards habe ich Grund anzunehmen, dass die hier nistenden uns nicht verlassen. So habe ich es zweifelsohne beobachtet, durch lange Jahre hindurch. Durchzügler kommen dagegen auch vor und sendet uns diese meistens der Norden; auch von diesen bleiben einige schon Winters über hier, verlassen uns aber wieder bei Eintritt milderen Wetters. Dank der Schonung, die der Bussard geniesst, hat er sich in den letzten Jahren ziemlich bedeutend vermehrt; von einer Schädigung der Jagd durch ihn kanu meines Erachtens überhaupt nicht die Rede sein, selbst wenn er bei Nahrungsmangel einmal ein krankes Rebhuhn schlägt. Sein Horst steht im Walde auf starken Bäumen, bisweilen aber auch auf einzelnen hohen Feldbäumen und enthält von Mitte April an sein volles, aus 2-3 Eiern bestehendes Gelege.

22. Buteo lagopus. Der Rauchfuss-Bussard kommt nur als Gast im Gebiete vor, aber keineswegs regelmässig.

23. Athene noctua. Das Käuzchen gehört wiederum zu unsern Brutvögeln und glaube ich wohl kaum, dass es in den Gärten irgend einer Ortschaft, wo es passende Plätze finden kann, fehlt. Mein Nachbargarten beherbergt z. B. ein Pärchen, das sich allabendlich, oft auch Tags uiber, durch seinen bekannten Ruf bemerklich macht.

24. Otus vulgaris. Die Waldohreule ist Brutvogel im Gebiet; als solcher tritt sie regelmässig, aber nicht häufig auf; häufig ist die Ohreule gelegentlich ihrer Wanderungen, dann trifft man oft grosse Flüge dieses Vogels an, wie sie Tags über der Ruhe pflegen in einem Dickicht. Die Waldohreule nistet in alten Krähen- oder Raubvogel-Horsten schon sehr zeitig im Frühjahr.

25. Otus brachyotus. Die Sumpfohreule gehört nicht zu den Brutyögeln unseres Gebietes, berührt aber alljährlich mit grosser Regelmässigkeit gelegentlich ihrer Wanderungen unser Gebiet, bald in grösseren Schaaren, bald in kleinern Flügen, bald nur einzeln.

26. Syrnium aluco. Der Waldkauz ist wieder Brutvogel und zwar brütet er regelmässig in unsern Wäldern, tritt jedoch auch keineswegs häufig auf. Winters über verlässt uns der Waldkauz auch nicht, obgleich manchmal seine Anzahl verstärkt wird durch Verwandte aus dem Norden. Seine Eier legt der Waldkauz 
in Baumlöcher und fand ich einst die Eier in einem hohlen Wurzelstock, wohin der Vogel nur von ebener Erde aus gelangen konnte. Das Gelege besteht aus 5-6 Stück und ist in der ersten Hälfte des Monats April vollzählig.

27. Strix flammea. Die Schleiereule zählt zu unsern ständigen Brutvögeln und darf man in den Ortschaften, wo sie passende Wohnplätze finden kann, mit Sicherheit auf ihr Vorkommen rechnen; ausserhalb der Ortschaften, wie z. B. im Walde, habe ich sie niemals angetroffen. Diese Eule verlässt das einmal erwählte Wohngebiet nicht im Winter, sondern hält beständig aus. Sie nistet im Gebälk und in Mauerlöchern alter Gebäude, Scheunen, und Kirchen. Ein merkwürdiger Umstand ist mir aufgefallen, der das Brutgeschäft dieses Vogels kennzeichnet; ich habe öfter in ein und demselben Neste frische und stark bebrütete Eier, neben jungen Nestvögeln gefunden, welche auch wiederum in verschiedenen Altersstufen vorhanden waren.

28. Luscinia vera. Die Nachtigall gehört zu unsern ständigen Brutvögeln; sie kommt jedoch nicht überall an den ihr passenden Oertlichkeiten vor, sondern ist sehr unregelmässig vertheilt. Am häufigsten ist sie in den zwischen Gronau und Hildesheim liegenden Waldungen, dort aber auch wiederum nur auf gewisse Gebiete beschränkt. Ziemlich häufig tritt sie auch an den Flussufern und im Park zu Banteln auf. Im Anfang Mai oder zu Ende April trifft sie wieder aus ihrer Winterherberge bei uns ein und verweilt bis in den September. Ihren Schlag lässt die Nachtigall nur während der Brutzeit und vor derselben hören; derselbe ist sehr verschieden in seiner Qualität; man vernimmt oft neben einem guten Sänger den Schlag eines argen Stümpers. Die Nachtigall nistet mehr am Boden, baut ein charakteristisches Nest, gross und locker, aus dürren Grasblättern und legt um Mitte Mai 4-5 Eier.

29. Erithacus rubвcula. Das Rothkehlchen ist ständiger Brutvogel des Gebietes, welcher im Herbst sich auf die Wanderschaft begiebt, jedoch auch in einzelnen Exemplaren in milden Wintern hier aushält. Die grosse Menge zieht im October durch und kommt im April wieder zurück. Zur Brutzeit zieht es den Waldrand oder parkähnliche Gartenanlagen vor; hier nistet es in Astlöchern und unter resp. in Erdufern; das Gelege enthält 5 bis 7 Eier.

30. Ruticilla phoenicura. Der Gartenrothschwanz tritt 
als ständiger Brutvogel im Gebiet auf, ist jedoch keineswegs häufig zu finden; er bewohnt die Gärten und den Waldrand und meidet die Wohnungen der Menschen. Im Herbst, je nach der Witterung, jedoch meist viel zeitiger als sein Vetter, verlässt uns der Rothschwanz gewöhnlich im October und trifft im April oder Mai wieder bei uns ein. Er nistet in Mauer- oder Astlöchern und unter überhängendem Wurzelwerk $u$. dgl. $\mathrm{m}$. und legt um Mitte Mai 5-7 Eier.

31. Ruticilla titys. Der Hausrothschwanz ist ebenfalls ständiger Brutvogel im Gebiet und ist mehr in der Nähe von menschlichen Wohnungen, Ställen, Schuppen u. dgl. m. anzutreffen. Er erscheint ungefähr in der.zweiten Hälfte des April, verlässt uns oft erst spät im Herbst, wie ich beobachtete; in der Regel kann man spätestens Ende October die letzten abziehen sehen; aber einzelne halten noch länger aus. Der Hausrothschwanz nistet in Mauerlöchern an Gebäuden oder im Innern derselben auf Balkenköpfen, Trägern, in Löchern u. s. w. und legt 4-5 Eier. Mit Gewissheit kann ich behaupten, dass zum Oeftern ein Pärchen in einem Sommer 2 Bruten grossgezogen hat.

32. Saxicola oenanthe. Der Steinschmätzer ist Brutvogel im Gebiet; an Chausseen mit Steinhaufen und in Steinbrüchen begegnet man ihm, jedoch immer nur in vereinzelten Pärchen. Etwas häufiger tritt er im Spätsommer und im Herbst gelegentlich seiner Wanderungen auf. Er nistet in Erdlöchern und Steinhaufen.

33. Pratincola rubetra. Der Wiesenschmätzer ist bei Weitem häufiger, als der Steinschmätzer und zählt auch zu den ständigen Brutvögeln des Gebietes. Er erscheint bei uns zu Anfang, resp. in der ersten Hälfte des Monats Mai und verlässt uns im September oder zu Anfang October. Der Wiesenschmätzer bevorzugt als Aufenthaltsort mehr die feuchten Wiesen, Graswege und breituferige Gräben. Auch er besitzt, gleich dem Steinschmätzer, eine grosse Vorliebe für hervorragende Sitzplätze und ist, wie jener, äusserist scheu und vorsichtig. Sein Nest legt der Wiesenschmätzer sehr versteckt auf dem Boden im Grase an; Anfangs Juni oder Ausgangs Mai legt er 5-6 Eier.

34. Turdus merula. Die Amsel.

35. Turdus musicus. Die Singdrossel.

36. Turdus viscivorus. Die Misteldrossel.

Die Amsel und Singdrossel gehören zu den regelmässigen oder ständigen Brutvögeln, während die Misteldrossel nur in einzelnen 
Jahren im Gebiet gebrütet hat. Die Singdrossel verlässt uns im Anfang October und kehrt im März zurück; dagegen Amsel (wenigstens die Männchen) und Misteldrossel bleiben Winters über hier, von der letztern wenigstens sieht man häufig im Winter Exemplare. Schon sehr früh im Jahre lässt die Schwarzdrossel ihre schönen Weisen erklingen, uns dadurch verkündend, dass der Frühling naht oder ihr liebes Weibchen zurückgekehrt ist; später, wenn die Singdrossel zurück ist, erfüllt diese im Verein mit der Amsel den Wald mit ihrem Gesange. Das Brutgeschäft beginnt zuerst die Amsel, dann folgt die Misteldrossel und endlich die Singdrossel. Amsel und Singdrossel bauen meist 1--21/2 Meter über dem Boden in dichtbelaubte trockene Büsche, oder in Reisighaufen; die Misteldrossel baut auf Bäumen, selten unter 3 Meter hoch vom Boden.

37. Turdus iliacus. Die Rothdrossel.

38. Turdus pilaris. Der Krammetsvơgel.

Die Rothdrossel und der Krammetsvogel berühren unser Gebiet nur auf ihren Wanderungen und brüten, soweit mir bekannt ist, nicht hier. Zuerst erscheint im Herbst der Krammetsvogel und nach ihm der Weinvogel oder Rothdrossel. Der Hauptmonat ist der October in denen sie durchziehen und März oder April der der Rückreise.

39. Troglodytes parvulus. Der Zaunkönig gehört zu den ständigen Brutvögeln des Gebietes und tritt als solcher nicht selten auf, obschon, wenn er nicht gerade singt, er leicht übersehen wird. Dichte Hecken und gleiches Buschwerk sowie hohle, überhängende Ufer, welche Wasser in der Nachbarschaft haben, sind seine Lieblingstummelplätze. Sein Gesang ertönt fast das ganze Jahr hindurch, trotz Schnee und Eis, und oft hört man den kleinen muntern Gesellen ganz in der Nähe, ohne ihn zu Gesicht bekommen zu können. Er nistet überall: in verlassenen oder wenig besuchten Kellern, in Mauerlöchern, in Uferlöchern oder unter überhängendem trockenem Erdufer, in oder unter Strohdächern und freistehenden Baumstämmen auf Astwerk. Das Nest hat stets eine Decke, die entweder durch die Natur (Mauer-oder Ufer-Loch) oder durch den Niststoff bei freistehenden Nestern künstlich gebildet ist. Im Anfang Mai oder zu Ende April legt der Zaunkönig 6-9 Eier.

40. Sylvia atricapilla. Der Mönch ist ständiger Brutvogel und die häufigste Grasmückenart der Wälder; Laubwaldungen, 
wo hohe'Bäume niedriges, buschartiges Unterholz bedecken, sind sein Lieblingsaufenthalt, zumal wenn einzelne Partien junger Tannen eingesprengt sind; reine Nadeldickichte scheint er zu meiden. Auch in Parkanlagen trifft man ihn und fühlt er sich hier ebenso wohl wie im Walde. Winters über verlässt er uns und zwar im October oder Ausgang September und kehrt in der zweiten Hälfte April zurück. Der Gesang dieser Grasmücke ist der schönste von den hier vorkommenden Grasmüken-Arten; und wiederum ist der Gesang des Mönches der Gebirge um ein bedeutendes schöner als der Gesang derer, die in der Ebene vorkommen. Sein Nest steht, wo er es haben kann, in einer jungen Tanne oder sonst in einem dichten Busche, ist locker gebaut und enthält im Anfang Mai 4 bis 5 Eier.

41. Sylvia cinerea. Die graue Grasmücke ist ebenfalls ständiger Brutvogel im Gebiet und sie tritt an den ihr zusagenden Oertlichkeiten ebenfalls häufig auf. Ihr Wohngebiet sind sowohl die Gärten und das Feld mit dichtem Gestrüpp und Hecken als auch der Wald. In den ersten Tagen des Mai trifft sie hier ein und verlässt uns im September wieder. Ihr Gesang ist einfach und erreicht bei Weitem nicht den des Mönchs. Sie nistet in dichtem Gestrüpp niedrig bis höchstens $1 / 4$ Meter über dem Boden und verwendet auch Thier- und Pflanzenwolle zum Bau, jedoch ist das Nest stets als Grasmücken-Nest zu erkennen. In der ersten Hälfte des Mai findet man das volle Gelege, welches aus 4-6 Eiern besteht.

42. Sylvia curruca (garrula). Diese Grasmücke tritt nicht so häufig auf als die beiden vorhergehenden; aber sie ist doch ständiger Brutvogel im Gebiet. Sie hat fast dieselben Wohnplätze wie die graue Grasmücke, scheint jedoch mehr den Wald zu meiden. Sie erscheint bereits gegen Mitte April, also am frühesten von den Grasmückenarten, und verlässt uns erst wieder im October. Sie baut das leichtfertigste Nest von allen Grasmücken und legt schon Ende April oder spätestens Anfang Mai 4 bis 5 Eier.

43. Sylvia hortensis. Die Gartengrasmücke ist ebenfalls Brutvogel im Gebiet und kommt in ziemlich gleicher Anzahl wie die vorige vor. Ihr Wohngebiet erstreckt sich hauptsächlich auf die Gärten mit dichten Hecken und Gebüschen. Sie kommt und geht so ziemlich mit der grauen Grasmücke: Anfang Mai erscheint sie und verschwindet im September. Sie nistet in Dornhecken der 
Gärten, meist in Meterhöhe über dem Boden; um Mitte Mai ist das Gelege, 4-6 Stück, vollzählig.

44. Hypolais icterina. Der Gartenspötter zählt zu unsern ständigen Brutvögeln. Sein Wohngebiet sind die Gärten, wo Obst- oder andere Bäume einige dichte Büsche oder Hecken bedecken. Hier trifft er um Ende April oder Anfangs Mai ein und macht sich gleich durch seinen Gesang bemerkbar. Sein Gesang ist bei weitem schöner als der der Grasmücken, mit Ausnahme des Mönchs, und er lässt ihn hauptsächlich zur Zeit des Fortpflanzungs-Geschäftes ertönen; unter Gesang-Begleitung baut sein Weibchen das künstliche Nest, mit Gesang greift er den Nebenbuhler an und vertreibt ihn. Sein Nest steht in einem dornlosen Busche oder auf Wipfelzweigen der Obstbäume, wird in ungefähr 12 Tagen fertig gebaut und enthält Ende Mai 5 Eier.

45. Phyllopneuste rufa. Der Weidenlaubsänger ist die am häufigsten hier vorkommende der drei Arten und zählt zu unsern ständigen Brutvögeln. Der Wald, hauptsächlich der gemischte, und die Parkanlagen sowie Gärten mit etwas Unterholz machen sein Wohngebiet aus. Im März erscheint er bei uns und verlässt uns erst wieder im October; er weilt also am längsten bei uns. Sein Nest, ein backofenförmiger Bau, steht meist in dichten Tannenzweigen 1/4-1 Meter über dem Boden und enthält Anfang Mai 6-7 Eier.

46. Phyllopneuste sibilatrix, der Waldlaubsänger, und

47. Phyllop neuste trochilus, der Fitislaubsänger, sind beides Brutvögel des Gebietes, welche beide im Monat April bei uns eintreffen und im September uns verlassen. Beide kommen in Laubwäldern vor, der erstere ausschliesslich und der letztere liebt auch gemischte Bestände. Sie nisten auf dem Boden und bauen ebenfalls backofenförmige Nester. Ihre Gelege findet man in der letzten Hälfte des Monats Mai oder auch zu Anfang Juni.

48. Regulus cristatus und

49. Regulus ignicapillus.

Das Winter- und das Sommer-Goldhähnchen zählen zu unsern Gebietsbewohnern, jedoch kann ich mit Bestimmtheit nur von R. ignicapillus angeben, dass er ständig im Gebiet brütet. Ich muss es einstweilen dahingestellt sein lassen, ob nicht auch die andere Species hier wenigstens ab und zu brütet. Im Sommer treten beide Arten ziemlich häufig auf; indem sie nur wenig Ansprüche machen, sind sie oft schon mit einer Tanne zufrieden, 
Die Brutvögel u. Gäste der Umgegend Gronau's in Hannover. 381

welche sie die Kreuz und Quere nach Insecten-Eiern und - Larven absuchen; denn Tannen geben sie unter allen Baumarten den Vorzug und bilden Tannenwälder ihren eigentlichen Aufenthaltsort. In den Spitzen der Tannenzweige bringt das Goldhähnchen auch sein zierliches und sehr kunstvoll gebautes Nest an, welches meist an einigen in den Rand eingeflochtenen Zweiglein aufgehängt ist und von einem darüber hinlaufenden grössern Zweige gedeckt wird; auf diese Weise ist das Nest schwer zu finden und für vierfüssige Räuber unerreichbar. Im Mai enthält das Nest das volle aus 7-9 Eiern bestehende Gelege; diese Eier sind die kleinsten aller einheimischen Vögel.

50. Acrocephalus arundinaceus. Der Teichrohrsänger ist eine nicht seltene Erscheinung in dem Rohr unserer Teiche und wo ihm dieses fehlt, begnügt er sich auch mit Buschwerk in der Nähe der Teiche. Jedenfalls scheint das Vorhandensein von stehendem Gewässer Lebensbedingung für ihn zu sein, denn er fehlt dort, wo das Teichrohr auf trockenem Untergrund wächst. Im Frühjahr erscheint der Teichrohrsänger im Anfang Mai und geht im August wieder fort. Der Teichrohrsänger baut sein Nest zwischen senkrechte Stengel des Teichrohres über der Wasserfläche oder in Ermangelung dessen im, dem Teiche benachbarten Buschwerk und in der zweiten Hälfte des Mai enthält das Nest 4-5 Eier.

51. Acrocephalus palustris. Der Sumpfrohrsänger ist ständiger Brutvogel im Gebiet und tritt als solcher an ihm passenden Oertlichkeiten sehr häufig auf. Er erscheint um Mitte Mai und geht bereits im August wieder fort. Sein Aufenthaltsort ist sumpfiger Boden mit Sumpfgewächsen oder Schnittweiden bestanden; hier baut er auch sein Nest und dieses zwar stets über trockenem Untergrunde. Zu Anfang Juni findet man sein volles Gelege bestehend aus 4-5 Eiern. Eine ausführlichere Beschreibung habe ich im Ornithologischen Centralblatt No. 19, Jahrgang 1882 gegeben.

Von den übrigen für Deutschland aufgeführten Acrocephalusund Locustella-Arten habe ich bislang nichts vernommen; ob sie aber gänzlich unserm Gebiete fehlen, oder ob nicht die eine oder die andere Art dennoch vorkommt und von mir bis jetzt übersehen ist, will ich dahingestellt sein lassen.

52. Accentor modularis. Die Heckenbraunelle zählt ebenfalls zu den ständigen Brutvögeln des Gebiets und tritt nicht 
selten auf. Dichte Gebüsche und Hecken, welche Wasser in der Nähe haben, bilden ihren Aufenthaltsort. In der ersten Hälfte des April trifft die Heckenbraunelle bei uns ein und verlässt uns im October. Ihr Nest steht in einer Hecke, einem dichten Busche oder Reisighaufen und enthält zu Anfang Mai 4-6 Eier.

53. Motacilla alba. Die Bachstelze.

54. Motacilla sulphurea. Die Gebirgsstelze.

55. Budytes flavus. Die Schaafstelze.

Die drei Stelzenarten sind sämmtlich ständige Brutvögel unseres Gebietes; am häufigsten tritt $M$. alba auf, wenigèr häufig $B$. Alava und am wenigsten häufig $M$. sulphurea. Die Bach- und Gebirgsstelze treffen zuerst im Frühjahr bei uns ein, nämlich erstere im März, letztere zu Anfang des Monats April; die Schaafstelze stellt sich selten vor Ende April ein. In umgekehrter Reihenfolge verlassen sie uns im Herbst: die Schaafstelze im August oder in der ersten Hälfte des September; die Gebirgsstelze im September und October und die Bachstelze ebenfalls im October. Bei den beiden letzteren kommt es vor, dass man bei uns auch im Winter ein oder das andere Exemplar für einen oder zwei Tage beobachten kann; darauf aber verschwindet dasselbe und Niemand weiss, woher es kam, noch wohin es ging. Die Bach- und Gebirgsstelze lieben sehr die Nähe des Wassers, während die Schaafstelze schon mehr feuchten Wiesen den Vorzug giebt. Bachstelze und Gebirgsstelze nisten unter Ufern, in Erd- und Mauerlöchern, während die Schaafstelze auf dem Boden in dichtem Pflanzenwerk oder an Böschungen nistet. Die Bachstelze legt im April 5-6 Eier; die Gebirgsstelze ebenfalls 4-5 Eier im April und die Schaafstelze legt erst gegen Ende Mai ihre 4-5 Eier.

56. Anthus arboreus. Der Baumpieper ist wohl die einzige Pieper-Art, von der ich mit Bestimmtheit sagen kann, dass sie bei uns ständig brütet. Der Baumpieper tritt uiberall bei uns im Walde auf an den Stellen, die ihm zusagen: Unterholz mit höheren Bäumen darin, jedoch darf ersteres nicht hoch sein und muss licht stehen. Der Baumpieper erscheint bei uns im April und verlässt uns im September bereits wieder. Er nistet auf dem Boden meist an Grabenrändern oder andern Böschungen, oder sehr versteckt an einem alten Baumstumpf oder im Grase und im Haidekraut; zu Anfang Mai findet man sein volles aus 4-5 Eiern bestehendes Gelege; ich habe auch noch in der zweiten Hälfte des Juni ein frisches Gelege gefunden. 
Die Brutvögel u. Gäste der Ungegend Gronau's in Hannover. 383

57. Alauda arvensis. Die Feldlerche ist einer der häufigsten ständigen Brutvögel im Gebiet. Gegen Anfang bis Mitte März trifft die Lerche hier ein und verweilt bis spät in das Jahr hinein, denn sie geht selten vor Ende October. Anderseits aber geschieht es auch, dass man in nicht allzustrengen und nicht schneereichen Wintern die Lerche fast das ganze Jahr beobachten kann; jedoch sind die Wintergäste alsdann solche, welche der Norden uns gesandt hat. In Getreidefeldern und Wiesen findet man das Nest auf dem Boden, meist im März und um Ende Juni das zweite Nest; 5-6 Eier bilden das Gelege.

58. Alauda cristata. Die Haubenlerche darf ich ebenfalls zu unsern ständigen Brutvögeln rechnen, sie tritt jedoch bei weitem nicht so häufig auf, als die Feldlerche. Im Winter zwar wird ihre Zahl durch Zuzügler verstärkt, aber im Sommer kommen die Pärchen doch nur sehr spärlich vor. Mir ist es noch nicht gelungen, ein Nest 'der Haubenlerche aufzufinden.

59. Emberiza schoeniclus. Der Rohrammer gehört zu den ständigen Brutvögeln des Gebietes und tritt als solcher an sumpfigen Orten, wèlche mit hohen Sumpfgewächsen bestanden sind, ziemlich häufig auf; jedoch beschränkt sein Vorkommen sich nur auf die Flussniederungen. Etwa zu Ende März oder Anfang April kommt der Rohrammer hier an und verlässt uns im Oetober. Ende April ist sein Gelege von 4-5 Eiern vollzählig und findet man das Nest auf dem Boden sehr versteckt im dürren Grase oder Schilf. Ich beobachtete, dass, nachdem ich das of vom Neste gestört hatte, das ơ auf den Eiern brütend sass und war dieses in den Mittagsstunden.

60. Emberiza miliaria. Der Grauammer ist ein bäufiger ständiger Brutvogel, welcher im Gebiet regelmässig vertheilt ist und nur nicht im Walde sich aufhält. Der Grauammer hält Winters über auch aus, jedoch schlagen sie sich mit den Goldammern in grosse Flüge zusammen und werden noch ausserdem durch $\mathrm{Zu}$ zügler verstärkt. Diese Flüge streifen umher, sich ihre Nahrung heute hier morgen dort zu suchen. Er nistet auf oder dicht uiber dem Boden im Gebüsch oder dichten Grase, zum ersten Male im April, zum zweiten Male im Juni, und belegt das Nest mit 4 bis 5 Eiern.

61. Emberiza citrinella. Der Goldammer ist ein ständiger Brutvogel des Gebietes, welcher sehr häufig auftritt in Feld und Wald. Auch er hält Winters über, in grossen Flügen vereinigt, 
bei uns aus und besucht dann die Gehöfte und den frisch gestreuten Dünger der Aecker; diese Flüge wandern, Nahrung suchend, im Gebiet umher. Sein Nest steht in dichten Gebüschen und Hecken, oft dicht über oder auf der Erde; in der zweiten Hälfte des Monats April ist sein aus 4-5 Eiern bestehendes Gelege vollzählig und im Juni folgt die zweite Brut.

62. Fringilla coelebs. Der Buchfink ist als ständiger Brutvogel regelmässig im Gebiet verbreitet und tritt ziemlich häufig auf. Sein Aufenthaltsort ist der Wald sowohl, wie die Obstgärten und die hohen Weiden an dem Strandufer. Der Buchfink hält auch Winters über in seinem Wohngebiet aus oder sucht ebenfalls mehr die Nähe der Menschen auf und stellt sich somit auch in den Gehöften in oft beträchtlicher Anzahl ein. Im April schreitet der Buchfink zum Nestbau und in der zweiten Hälfte dieses Monats findet man 4-6 Eier in dem Neste.

63. Fringilla montifringilla. Der Bergfink ist nur als Wintergast im Gebiet beobachtet, welches er fast allwinterlich in mehr oder weniger grossen Flügen besucht.

64. Chrysomitris spinus. Der Zeisig ist ebenfalls nur als Wintergast im Gebiet beobachtet; er erscheint ebenfalls meist in Flügen von grösserer oder geringerer Anzahl.

65. Carduelis elegdns. Der Stieglitz ist ständiger Brutvogel im Gebiet und tritt überall in Parkanlagen und Obstgärten auf. Der Stieglitz verlässt uns nicht im Winter, sondern streift in kleinen Gesellschaften in den Feldern umher, um die Disteln nach Samen abzusuchen. Ende April und Anfang Mai beginnen sie mit dem Nestbau, der regelmässig 10-14 Tage dauert; das Nest steht meist auf Obst-Bäumen, auf den Spitzen dichtbelaubter Zweige ziemlich gut verborgen. Im Mai findet man 4-6 Eier im Neste. An dem Stieglitz habe ich beobachtet, dass er, als ich ihm sein Gelege genommen hatte, den Niststoff, welcher eben verbaut war, von seinem Neste nach und nach wieder fortholte und zum Bau des neuen Nestes verwandte; von dem Neste, aus dem ich die Eier genommen hatte, war nach einigen Tagen fast nichts mehr vorhanden.

66. Cannabina linota. Der Hänfling ist ständiger Brutvogel im Gebiet und tritt als solcher ziemlich häufig auf in Gärten, grössern Buschwerken, im Walde und Parkanlagen. Der Hänfling bleibt im Winter, zum Theil in kleine Gesellschaften vereinigt, bei uns; ein grosser Theil aber begiebt sich auf die Wanderschaft. 
Im April beginnt der Hänfling mit dem Nestbau meist in einem dichten Weiden-, Dorn-, Stachelbeer- oder Johannisbeer-Busch, auch junge dichte Tannen liebt er sehr und bevorzugt er im Walde solche fast immer; zu Anfang Mai findet man sein volles Gelege von 4-6 Eiern. Nach der Brutzeit und im Herbst schlagen sie sich zu Gesellschaften zusammen und beginnen ihre Streifereien.

67. Ligurinus chloris. Der Grünling ist ständiger Brutvogel im Gebiet und ist ziemlich häufig in Obstgärten, Parkanlagen und den mit jungen Tannen durchsetzten Waldtheilen. In der Winterszeit verhält er sich wie der Hänfling; bisweilen erscheinen kleine Gesellschaften dieses Vogels und verschwinden bald darauf wieder. Der Grünling nistet meist hoch, selten unter $1 \frac{1}{2}$ Meter bis 2 Meter: Junge Tannen in dieser Höhe, dichte Bäume, hauptsächlich die gekappten Eschen, Weiden, Hainbuchen u. s. w. dienen zur Aufnahme seines Nestes, welches im April gebaut wird und zu Anfang Mai spätestens das volle, aus 4-6 Eiern bestehende Gelege enthält.

68. Pásser domesticus. Der Hausspatz.

69. Passer montanus. Der Feldspatz.

Beide Arten kommen häufig im Gebiet vor, die erste mehr in den Ortschaften, die zweite Art auch an passenden Stellen im Felde; beide Arten machen jedenfalls zwei Bruten. Im Winter kommen beide auf die Gehöfte.

70. Coccothraustes vulgaris. Der Kernbeisser ist ständiger Brutvogel im Gebiet, scheint jedoch als solcher nicht überall verbreitet, sondern der Wald und die demselben benachbarten Obstgärten bilden seinen Aufenthaltsort. Von hier aus durchstreift er das ganze Gebiet, zumal zur Zeit der Kirschreife. Sein Nest steht auf Obstbäumen oder dichtbelaubten andern jungen Bäumen, selten unter Mannshöhe und enthält zu Anfang Mai 4 bis 5 Eier. Höchst wahrscheinlich findet eine zweite Brut statt im Juli, da ich schon in der zweiten Hälfte dieses Monats des öftern halbflügge Junge im Neste fand.

71. Pyrrhula europaea. Der Gimpel ist im Gebiet ständiger Brutvogel; vor 10-12 Jahren war er noch häufiger, aber seitdem hat er in gewissen Theilen unseres Waldes sehr abgenommen. Als Brutvogel kommt er ausschliesslich im Walde oder in dichtem Feldgehölz vor, in der übrigen Zeit streift er umher und besucht dann gelegentlich die Obstgärten; auch Winters über streift der Gimpel im Gebiet umher. Er liebt sehr die Nähe des 
Wassers und bevorzugt Waldungen, wo Laub- und Nadelholz dichte Gehege bilden. In einem dichten Busche oder einer jungen Tanne baut er sein Nest, welches aus Würzelchen aufgebaut wird, die, jemehr der Nestmulde zu, immer zarter werden. Im Mai findet man seine 4-5 Eier.

72. Sturnus vulgaris. Der Staar gehört zu den häufig auftretenden regelmässigen Brutvögeln des Gebietes. In den Ortschaften und tiefer im Walde trifft man ihn zur Brutzeit an; sonst pflegt er aber in grossen Schwärmen die Felder und Viehweiden zu besuchen. Im Frühjahr sehr zeitig stellt sich der Staar ein und verlässt uns im Herbst mit dem October resp. Anfang November. Vor der Ankunft der Hauptmasse im Frühjahr sieht man oft ein halbes Dutzend Staare an ihren Brutplätzen verweilen, sich einige Tage aufhalten und wieder verschwinden; meist stellt sich dann später auch wieder rauhes Wetter ein. Der Staar ist Höhlenbrüter; Löcher in Mauern, Staarkübel, Astlöcher u. dgl. m. benutzt er zur Anlage seines Nestes, welches er im April mit 5-6 Eiern belegt; im Juni wird eine zweite Brut gemacht, aus 4-5 Eiern bestehend.

73. Corvus cornix. Die Nebelkrähe.

74. Corvus corax. Der Kolkrabe.

Diese beiden Rabenarten kann ich einstweilen nur als Gäste aufführen, von denen uns wenigstens der erstere regelmässig allwinterlich besucht; der Kolkrabe kommt weit seltener auf seinen Wanderungen hier durch. Die Nebelkrähe trifft schon im September ein und verweilt bis in den Februar oder März.

75. Corvus monedula. Die Dohle ist Brutvogel in unmittelbarer Nachbarschaft, in Hildesheim nistet sie nämlich an mehreren Kirchen. Als Gast durchstreift sie häufig unser Gebiet, ist aber von mir noch nirgends brütend angetroffen.

76. Corvus corone. Die Rabenkrähe hatte von den Verwandten bislang allein das Vorrecht, ein ständiger Brutvogel des Gebietes zu sein; seit einem Jahre hat sich die Saatkrähe ihr beigesellt. Die Rabenkrähe bevorzugt die Feldhölzer, oder wo diese fehlen begnügt sie sich mit einzeln hohen Bäumen, wie sie z. B. an den Ufern der Leine zu finden sind. Ihr Nistgeschäft beginnt zu Ende März oder Anfang April; den ebengenannten Oertlichkeiten giebt sie den Vorzug, aber auch im Waldrande findet man gelegentlich ihr Nest. Die Eier, $4-6$ an Zahl, findet man in der ersten Hälfte des April. 
77. Corvus frugilegus. Die Saatkrähe hat sich erst im Frühjahr 1882 als Brutvogel im Gebiet eingestellt, zum grössten Aerger (!) der hiesigen Landwirthe. Diese Ansiedelung befindet sich in einem Complex hoher Weiden an den Leineufern und bestand aus ca. 80-90 Nestern; wie viele deren in diesem Frühjahr wieder bezogen werden, ist noch nicht zu bestimmen. Schon Anfang März wurden von den Saatkrähen die ersten Niststoffe eingetragen, während erst zu Ende Mai resp. Anfang Juni die Nestjungen auf dem Nestrande erschienen. Es ist sehr schwierig, zu den Nestern zu gelangen, da sie auf den höchsten Aesten der Bäume angebracht sind.

78. Nucifraga caryocatactes. Der Tannenhäher ist ein sehr selten erscheinender Gast des Gebietes, denn meines Wissens nach ward ein Exemplar vor langen Jahren im Gebiet geschossen und seitdem habe ich nichts wieder davon gehört.

79. Pica caudata. Die Elster gehört zu unsern regelmässigen Brutvögeln; jedoch tritt sie keineswegs häufig auf, wie noch vor 10-12 Jahren, sondern nur sehr vereinzelte Pärchen sind es, die man vorfindet. Sie gehört auch zu den Vögeln, welche in dem einmal gewählten Gebiete auch Winters über sich aufhalten. Die Elster bevorzugt als Wohngebiet die Obstgärten der Dörfer, oder die lichten Bestände von Feldbäumen; ganz kleine Feldgehölze werden auch von ihr und der Waldrand jedoch nur selten bewohnt. Sie nistet meist hoch auf Bäumen und baut ein festes Nest aus Dornenzweigen und Erde, welches oben von einer schützenden Dornhaube gedeckt wird. Im April findet man ihre 5-7 Eier.

80. Garrulus glandarius. Der Häher ist ein in unserm Walde überall verbreiteter ständiger Brutvogel, welchem man ziemlich häufig begegnet; er bevorzugt alle jüngern Bestände im Walde, wo er Deckung für sein Thun und Treiben finden kann. Von hier aus unternimmt der Häher oft grössere Streifzüge, welche im Sommer zunächst den reifen Kirschen gelten; dann aber begegnet man im Herbst und Frühjahr Gesellschaften, welche jedenfalls auf der Wanderung begriffen sind. Der Häher nistet im Walde in dem dichten Laubwerk der Bäume, meist gut versteckt und in über doppelter Manneshöhe; in der ersten Hälfte des April findet man das aus 5-7 Eiern bestehende volle Gelege.

81. Lanius excubitor. Der grosse Würger ist ebenfalls ständiger Brutvogel im Gebiet und ist das ganze Jahr über anzutreffen, obgleich ich nicht glaube, dass er sich im Winter auch auf 
das im Sommer innegehaltene Gebiet allein beschränkt. Das einmal gewählte Gebiet behauptet er, wenn ihn nicht unliebsame Störungen durch die Menschen anders bestimmen, viele Jahre lang hintereinander. Die Feldbäume, in deren Nähe Hecken und Dornengestrüpp wachsen, Parkanlagen und der Rand des Waldes bilden sein Quartier. So klein der Würger ist, um so grösser ist sein Muth; im Winter habe ich ihn öfters Vögel bis zu Sperlingsgrösse fangen, tödten und forttragen sehen, abwechselnd den Schnabel und die Füsse zum Tragen gebrauchend. Sein Nest steht in hohen und dichten Dornbüschen oder auf Bäumen und enthält von Mitte April an 5-7 Eier. An einem Würger-Pärchen habe ich beobachtet, dass, nachdem um Mitte Mai die Jungen der ersten Brut das Nest verlassen hatten, zu Ende Juni wiederum eine Brut, welche in derselben Hecke gezeitigt war, das Nest verliess; man kann daher mit ziemlicher Gewissheit annehmen, dass jenes Pärchen zwei Bruten gemacht hat.

82. Lanius collurio. Der Neuntödter ist ein ständiger Brutvogel des Gebietes und fast überall in den Dornengestrüppen, Obstgärten, Parkanlagen und Waldrändern zu finden. In der zweiten Hälfte des April oder zu Anfang Mai erscheint er und bleibt bei uns bis in den September hinein. Es ist oft wunderbar, wie der Neuntödter sich Mühe giebt, die Nester der kleinen Sänger etc. auszukundschaften. Sieht er in einem Busche von seiner Warte aus einen solchen Vogel sich zu schaffen machen, so ist er gleich da, um den Busch auf seinen Inhalt an Nestern zu untersuchen. Ich habe ihn nirgends geduldet, wo es mir auf Vermehrung der Singvögel etc. ankam. Er nistet in Dornbüschen vorzugsweise, sonst aber auch iu andern dichten Büschen und findet man gegen Mitte Mai das volle Gelege von 5-7 Eiern; letztere Zahl mag aber selten vorkommen, da ich erst einmal ein Gelege von 7 Stück ausgehoben habe.

83. Lanius senator (rufus). Der Rothkopfwürger ist vor längern Jahren von mir zwei Mal als Brutvogel angetroffen im Park zu.Haus-Escherde; seitdem hat er sich aber nicht wieder sehen lassen und ist es mir auch nicht bekannt, dass dieser Würger ebenso wie $L$. minor sonst im Gebiet wieder genistet hat.

84. Chelidon urbica. Die Mehlschwalbe ist ständiger Brutvogel des Gebietes und in allen Ortschaften mehr oder minder häufig vertreten. Sie erscheint bei uns meist in der zweiten Hälfte des April und verlässt uns im September. Ihre Anzahl hat in dem 
letzten Jahrzehnt ziemlich abgenommen, worin aber hierfür der Grund zu suchen ist, weiss ich nicht; jedenfalls trägt Verfolgung durch Menschen nicht die Schuld, da die Schwalbe im Volksmund „heilig“ ist. Die Mehlschwalbe baut ihr Nest aussen an die Gebäude und legt bis 5 Eier in der zweiten Hälfte des Mai.

85. Hirundo rustica. Die Rauchschwalbe ist ebenfalls ständiger Brutvogel im Gebiet; sie trifft stets vor der Mehlschwalbe, also in der ersten Hälfte des April ein und verweilt bis zu Ende September oder Anfang October. Diese Schwalbe ist in ihrem Bestande sich gleich geblieben oder hat sich eher etwas vermehrt. Die Viehställe sind ihre Wohnstätten; in diesen bringen sie auch ihre Nester an, in denen man in der ersten Hälfte bis Mitte des Mai das frische Gelege findet. Im Herbst 1879 habe ich eine fast reinweisse Rauchschwalbe erlegt, welche jedoch normal gefärbte Augen hatte.

86. Cotyle riparia. Die Uferschwalbe ist ständiger Brutvogel im Gebiet und ist am häufigsten an den Ufern der Leine. Sie tritt auch hier in grössern Colonien auf. Die steilen Uferwände oder Kiesgrubenwände nelımen die Nisthöhlen, welche bis 1 Meter tief und darüber sind, auf und in diesen Nestern findet man 4 bis 5 Eier. Die Zeit, um welche man die frischen Gelege findet, richtet sich danach, ob die Höhle neugegraben werden muss, oder ob eine alte schon vorhandene Höhle benutzt werden kann. Im ersten Falle fand ich noch zu Anfang Juli frische Gelege, im letztern Falle dagegen schon um Mitte Juni.

87. Muscicapa grisola. Der graue Fliegenschnäpper ist ständiger und nicht seltener Brutvogel des Gebietes, welcher überall in Gärten mit Obstbaumpflanzungen vorkommt, dagegen den Wald völlig meidet. Er trifft bei uns in der ersten Hälfte des Mai ein und verweilt bis gegen Ende September. In der zweiten Hälfte des Mai beginnt der Nestbau; Astlöcher, Mauerlöcher, Spalierstangen und -Bäumchen nehmen das Nest auf und dieses enthält gegen Ende Mai das frische Gelege aus 4-5 Eiern bestehend. Ein Pärchen dieses Vogels bauete in einem Frühjahr 3 Nester, da es zweimal gestört ward; das erste Nest enthielt am 31. Mai 5 frische Eier, das zweite Nest am 9. Juni 4 frische Eier und das dritte Nest ebenfalls 4 Eier; das letzte Gelege wurde glücklich ausgebrütet und die Jungen grossgebracht.

88. Muscicapa atricapilla. Diesen Fliegenschnäpper kann ich unsern Brutvögeln füglich zurechnen; aber nur sehr ver- 
einzelt trifft man die Pärchen an. So habe ich deren eins im Park zu Haus-Escherde beobachtet und, wie man mir sagte, soll sich dasselbe mehrere Jahre hintereinander dort gezeigt haben. Das Nest dieses Vogels habe ich bis heute noch nicht gefunden, kann auch nichts über Ankunfts- und Abzugs-Zeit angeben.

89. Ampelis garrula. Der Seidenschwanz darf nur zu den Gästen des Gebietes gerechnet werden; sein Vorkommen ist sehr selten und ist mir derselbe nur ein Mal bekannt geworden; mein Vater hat vor langen Jahren diesen Vogel in unserm Gebiet beobachtet und auch aus dem Schwarme einige geschossen, von denen noch 2 Stück in meiner Sammlung stehen.

90. Oriolus galbula. Der Pirol gehört zu den ständigen oder regelmässigen Brutvögeln des Gebietes, welcher zu Anfang Mai in seinem Wohnbezirk eintrifft und uns spätestens im Anfang September wieder verlässt. Sein Wohngebiet bilden der Waldrand, die Parkanlagen und vor Allem die am Flussufer stehenden hohen Weiden, sowie endlich die Obstgärten. Bald nach seiner Ankunft beginnt der Nestbau, welcher 10-14 Tage dauert; das Nest hängt in bedeutender Höhe in einer Astgabel und enthält zu Anfang Juni das frische Gelege von 4-5 Eiern.

91. Parus major, die Kohlmeise, und

92. Parus coeruleus, die Blaumeișe, sind die ständig als Brutvögel im Gebiet auftretenden Meisenarten. Beide Arten kommen nebeneinander und an denselben Oertlichkeiten vor: Im Walde, in Obstgärten und Parkanlagen. Im Winter verlassen sie ihr Wohngebiet wenigstens so lange nicht, als es ihnen ausreichende Nahrung bietet; sonst sieht man sie in Gesellschaften durch die Gärten und im Walde umher streifen. Beide Meisen sind Höhlenbrüter; alle Arten von Löchern in Bäumen und Mauerwerk von passender Grösse werden gern und oft mehrere Jahre hintereinander benutzt. Von 25 Centimeter über dem Boden bis an 8 bis 10 Meter hoch habe ich die Nester dieser Vögel gefunden, in welchen zu Ende des Monats April oder Anfangs Mai das volle Gelege sich befand.

93. Parus cristatus, die Haubenmeise.

94. Parus ater, die Tannenmeise.

Diese beiden Meisen treten hier im Sommer wie im Winter auf und glaube ich, dieselben brüten auch im Gebiet; sicher bin ich dessen allerdings nicht, da ich deren Nest noch nicht habe entdecken können. 
Die Brutvögel u. Gäste der Umgegend Gronau's in Hannover. 391

95. Acredula caudata. Die Schwanzmeise zählt zu den regelmässigen Brutvögeln des Gebietes, tritt aber nicht häufig auf; sie hält auch Winters über im Gebiet aus, jedoch unternimmt sie dann, zu kleinen Gesellschaften vereinigt, oft grössere Streifzüge. Meist im April beginnt die Schwanzmeise mit dem Bau ihres künstlichen Nestes, welches bald hoch auf Bäumen, bald niedrig in jungen Tannen oder Laubbüschen steht; es giebt Nester, welche als innere Ausstattung oft Federn von nur einer Vogelart enthalten, so fand ich einst ein solches, welches inwendig nur mit Federn von einer Ohreule ausgebaut war. Das Schlupfloch ist in fast allen Fällen in der Richtung zwischen Süden und Westen angelegt. Das Nest enthält zu Anfang Mai 8-12 Eier.

96. Sitta caesia. Der Kleiber gehört zu den regelmässigen Brutvögeln des Gebietes, welcher Winters über an seinem einmal gewählten Gebiete festhält. Sein Wohngebiet ist der Wald, die Parkanlagen und die in ihrer Nähe gelegenen Obstpflanzungen und -Gärten; immerhin jedoch tritt er nicht häufig auf. Die in seinem Wohngebiet gelegenen Astlöcher werden inspicirt auf ihre Brauchbarkeit zur Niststätte. Ist ein solches Loch mit einem zu grossen Schlupfloche versehen, so wird das letztere bis auf die gewünschte Grösse mit Lehm zugeklebt; ebenso verfahren sie, wenn die Wandungen der Nisthöhle Oeffnungen haben. Nach dieser Eigenschaft hat der Vogel den Namen Kleiber. Das Schlupfloch ist nicht immer kreisrund, sondern sehr oft oval, wie ich selbst beobachtet habe, und zwar in diesen Fällen breiter als hoch. In der zweiten Hälfte des April findet man das volle Gelege, 6-8 Stück; die Eier sind oft ganz durch das Nistmaterial, welches aus trockenen Blatt- und Baumrinden-Stücken besteht, zollhoch bedeckt.

97. Certhia familiaris. Der Baumläufer ist ebenfalls ständiger Brutvogel im Gebiete und bewohnt es Winters und Sommers über; er tritt in ungefähr gleicher Anzahl wie der vorige auf, ist aber stellenweise doch häufiger. Der Baumläufer bevorzugt mehr die Obstgärten, meidet jedoch den Wald nicht und kommt hier zumal im Hochwalde vor. Astlöcher, Baumspalten, Mauerritzen und bisweilen Dachsparren nehmen das Nest auf, welches im April das volle Gelege enthält.

98. Upupa epops. Vor ca. 10 Jahren gehörte der Wiedehopf noch zu den nicht seltenen Brutvögeln des Gebietes und brütete hier regelmässig. Heute ist er sehr selten geworden und glaube ich wohl kaum noch mit Sicherheit ihn als regelmässigen 
Brutvogel für unser Gebiet betrachten zu dürferı. Wiesen und Weiden mit Feldern abwechselnd und dazwischen alte Bäume mit passenden Nistlöchern, oder Viehweiden in der Nähe des Waldes sind sein Aufenthaltsort. Im Winter verlässt uns der Wiedehopf; etwa zu Anfang April kommt er hier an und geht im August oder September. Der Wiedehopf nistet in Baumlöchern.

99. Columba palumbus. Die Ringeltaube ist ständiger Brutvogel des Gebietes und tritt als solcher nicht selten auf. Ihr Wohngebiet sind ausschliesslich der Wald und die Feldhölzer, ausnahmsweise fand ich sie auch regelmässig im Park zu HausEscherde brütend; sie bevorzugt die älteren Bestände von Laubholz, zumal wenn gleiche Bestände von Nadelholz in denselben eingesprengt liegen. Im September und October zieht die Ringeltaube in grösseren Schaaren durch und kehrt im März oder April wieder zu uns zurück. Die Ringeltaube beginnt um April mit dem Bau ihres kunstlosen Nestes und belegt dasselbe mit zwei Eiern; das Nest wird meistens in ziemlicher Höhe über dem Boden angebracht; Nadelholzbäume erhalten den Vorzug, sonst aber werden dicht belaubte Laubbäume benutzt. Die Ringeltaube macht mehrere Bruten; ich fand einst am 6. October halbflügge Junge in einem Neste.

100. Columba oenas. Die Hohltaube tritt nur als Gast auf und zwar sieht man sie gelegentlich ihrer Herbstwanderungen, seltener im Frühjahr; sie tritt auch ziemlich regelmässig jeden Herbst auf.

101. Turtur vulgaris. Die Turteltaube gehört zu den ständigen Brutvögeln des Gebietes; sie tritt in ziemlich gleicher Anzahl wie die Ringeltaube auf. Auch sie bevorzugt den Wald und die Feldhölzer, zieht aber in diesen die Dickungen den lichten Beständen vor; sie hat auch grosse Vorliebe für gemischte Bestände. Die Turteltaube trifft immer etwas später ein, als die Ringeltaube, etwa in der ersten Hälfte des April, und im September verlässt sie uns wieder; in ihrem Wesen bekundet sie bei Weitem mehr Zutrauen zum Menschen, als die Ringeltaube. Sie nistet im dichten Gebüsch meist in Manneshöhe über der Erde; zum ersten Male legt das Weibchen im April, das zweite Mal im Juni seine 2 Eier in das äusserst kunstlose Nest.

102. Perdix cinerea. Das Rebhuhn ist regelmässig in unserm Gebiet verbreitet, soweit nicht der Wald ihm entgegentritt, und tritt iiberall als ständiger Brutvogel auf. In Betreff der Anzahl kann man sagen, dass es in einem Jahre häufig, im andern 
weniger häufig ist; im Ganzen aber hat seit Anfang der 70 er Jahre ihr Bestand abgenommen, wahrscheinlich in Folge der schlechten Winter. Das Rebhuhn welches bei uns brütet, ist entschieden Standvogel und hält beständig an seinem Wohngebiet fest, so lange nicht Nahrungsmangel eintritt. In Anbetracht des Ziehens oder Wanderus von Rebhühnern kann ich folgende Angaben machen: Unser Gebiet leidet nicht an Uebervölkerung, sondern alle Hühner werden den ganzen Winter über ihre Nahrung finden können; ich habe in Folge dessen auch niemals die Beobachtung gemacht, dass eine hier erbrütete Kette ihr specielles Wohngebiet für immer verlassen hätte, sich also somit auf die Wanderung begeben hätte. Allerdings liegt das im Frïhjahr, wenn die Hühner sich paaren, anders; da habe ich wohl schon beobachtet, dass von einem überwinterten Volke von 12-14 Stück oft nur noch 2 Pärchen an der gewohnten Stelle zu finden waren; die übrigen hatten denn natürlich ihr altes Wohngebiet verlassen müssen, gezwungen durch die stärkeren Hähne; wohin sie aber gegangen, ist nicht mit Bestimmtheit anzugeben, jedenfalls aber blieben sie in der Nachbarschaft, wo sich eben noch kein Paar angesiedelt hatte.

Anderseits habe ich, aber niemals vor Anfang October, grosse, 40-60 Stück zählende Hühnerschwärme gesehen, die Tags darauf oder kurze Zeit nachdem wieder verschwunden waren; oder ich habe die Beobachtung gemacht, dass zu Anfang October scheinbar mehr Hühner in meinem Jagdbezirke waren, als 4 Wochen früher. Dieses Letztere kann ja allerdings darin seinen Grund habẹn, dass, in Folge des allmählichen Verschwindens der Kartoffel- und Rübenfelder, die Hühner leichter gefunden werden können; aber wenn man 4 Wochen lang ein kleines Territorium fast täglich mit einem guten Hunde abgesucht hat, sollte man doch nicht annehmen, dass man eine solche Anzahl von Ketten nicht gefunden habe, dass deren Erscheinen später eine bedeutende Vermehrung hervorbringen könne. Vielmehr glaube ich, dass diese Verstärkung zu Anfang October durch Einwanderer hervorgerufen wird; und in diesem Glauben bin ich noch bestärkt durch das spätere Verschwinden der Hühner. Die Legezeit fällt in den Monat Mai, die Anzahl der in einem Neste gefundennn Eier schwankt zwischen 8 und 24 Stück; ob aber 24 Eier von einer einzigen Henne gelegt wurden, mag dahingestellt bleiben. Die Alten vertheidigen sehr muthig ihre Jungen gegen alles Raubzeug; ja sie haben meinen Hund attackirt, so dass dieser bei mir Schutz suchte. 
103. Coturnix communis. Die Wachtel zählt zu den ständigen Brutvögeln des Gebietes, tritt aber bei Weitem weniger häufig auf, als das Rebhuhn; ihr Aufenthalt bei uns erstreckt sich auf die Monate Mai bis August und September. Sie nistet gleich dem Rebhuhn im Getreide, Klee oder dichten Grase auf dem Boden und das Nest enthält zu Ende Mai oder Anfang Juni die vollen bis an 14 Eier zählenden Gelege.

104. Otis tarda. Die Grostrappe erscheint in strengen Wintern bei uns; so waren in den Wintern von 1878-1879, 1879-1880 und 1880-1881 hier die Trappen vertreten; ihre Anzahl war verschieden, ich habe einst einen Schwarm von 30 bis 40 Stück beobachtet. Die Raps- und Roggenfelder bildeten den Hauptanziehungspunkt und mit grosser Regelmässigkeit besuchten sie die erwählten Breiten.

105. Vanellus cristatus. Der Kiebitz brütet in einzelnen Pärchen in jedem Frühjahr im Gebiet; auf dem Durchzuge treten sie oft, zumal bei Frühjahrs-Hochwasser, in grossen Schaaren auf. Im März kommt er bei uns an und verweilt im Herbst bis in den October, je nach den Witterungsverhältnissen. In der Nähe von stehenden Gewässern legt der Kiebitz sein Nest an; Erdschollen auf Sturzäckern oder Brachfeldern werden benutzt, weil auf diesen der Vogel auf dem Neste freie Umschau halten kann und mehr gegen Feuchtigkeit von unten geschützt ist. Eine einfache Mulde, welche höchstens mit einigen Strohspieren belegt, nimmt die 3-4 Eier auf, welche im April gelegt werden.

106́. Charadrius fluviatilis. Der Flussregenpfeifer gehört auch unter die Brutvögel unseres Gebietes; sein Vorkommen erstreckt sich auf die Sandbänke der Leineufer; hier sieht man die munteren Vögel den ganzen Sommer uiber von Anfang Mai bis Ende August oder Mitte September. Die besagten Kiesbänke enthalten auch das Nest des Vogels: einfache Vertiefungen, in welchen 3-4 Eier liegen.

107. Scolopax rusticola. Die Waldschnepfe gehört zu den Brutvögeln des Gebietes; allerdings wird dieselbe wohl nicht regelmässig jedes Frühjahr bei uns zur Brut schreiten. Zu verschiedenen Malen hat sie aber, wie ich selbst beobachtet habe, im Gebiet gebrütet. Die Schnepfe erscheint im Frühjahr mit dem Eintritt des milden Wetters, also ungefähr um Mitte März, und man trifft sie noch 4 Wochen später ebenfalls hier auf dem Durchzuge an. Die Dauer des Durchzuges richtet sich aber sehr 
nach der Beschaffenheit des vorauf gegangenen Winters. Strenge und kalte Winter haben einen sogenannten "guten Zug“, milde Winter dagegen einen schlechten Zug im Gefolge. Wenn ein milder Winter voraufgegangen ist, so fangen die Schnepfen schon Ende Februar an hier durchzuziehen und dieses dauert bis Mitte April, man wird also immer nur eine geringe Anzahl des Vogels antreffen. Dagegen nach einem strengen Winter kommt bei Eintritt des milden Wetters, was sich oft erst um. Mitte März einstellt, die ganze Gesellschaft, welche durchziehen muss, fast gleichzeitig an und daher der „gute Strich“, wie die alten Jäger sagen; derselbe dauert dann natürlich nur einige Tage, während Nachzügler noch länger sich aufhalten. Der Herbstzug geht meist schnell von Statten, die Hauptmasse zieht in der ersten Hälfte des Oetober durch; einzelne sogenannte Lagerschnepfen bleiben bis spät in den Winter hinein und weichen erst, wenn ihnen Schnee und Kälte zu empfindlich werden. Im April schreitet sie zum Nestbau, eine vorhandene oder selbstgescharrte Mulde an schützender Stelle wird spärlich mit etwas Genist ausgepolstert und gegen Ende April mit 4 Eiern belegt.

108, Scolopax gallinaria. Die Beccassine berührt, soviel mir bekannt, unser Gebiet nur während der Zugzeit; ich habe sie immer nur im Herbst einzeln an stehenden Gewässern oder sumpfigen Stellen angetroffen.

109. Ciconia alba. Der weisse Storch ist Brutvogel im Gebiet; jedoch scheint er sich nicht behaglich genug gefühlt zu haben, denn nachdem sich ein Paar mehrere Jahre lang hintereinander in einem Dorfe angesiedelt hatte, ist er jetzt wieder ausgeblieben.

110. Ciconia nigra. Der schwarze Storch ist von mir in den letzten 12 Jahren fast allsommerlich beobachtet. Er begegnete mir mitten im Walde, an Stellen, wo sumpfige Wiesen gebildet wurden durch einen Wasserlauf, die Beuster; hier habe ich oft, gelegentlich des Anstandes auf Rehböcke, den schönen, scheuen Vogel beobachten können, welcher bisweilen höchstens 30 Schritt entfernt war. Im April erscheint der schwarze Storch und verweilt bis in den September. Bald nach seiner Ankunft schreitet das Paar zum Horstbau und um Ende April oder zu Anfang Mai findet man das volle Gelege. Ob der schwarze Storch in unserm Gebiete nistet, habe ich nicht aus eigener Anschauung erfahren, aber es ist mir fest versichert worden und auch glaublich, da ihm passende Oertlichkeiten zu Gebote stehen. 
111. Ardea cinerea. Der Fischreiher scheint vorläufig nur als Gast unser Gebiet zu berühren und zwar sowohl im Winter als während des Sommers; in der Nachbarschaft (bei Alfeld) soll sich eine Reihercolonie befinden und mag von dort her unser Gebiet wohl besucht werden; im Gebiet selbst nisten sie nicht. Im Herbst, wenn sie gegen Süden wandern, im September und October, sieht man bisweilen Gesellschaften von 12-14 Stück beisammen, sonst aber tritt der Reiher nur einzeln, höchstens zu 3-4 vereinigt auf. In milden Wintern, wie $1881-1882$, bleiben einzelne Reiher hier; in diesem Winter (1882-1883), welcher doch bisweilen an $6-8^{\circ}$ unter Null aufzuweisen hatte, sind die Reiher, 4-5 Stück, auch hier geblieben; tagtäglich habe ich Gelegenheit gehabt sie zu beobachten.

112. Arde a minuta. Die Zwergrohrdommel ist vor längern Jahren im Röhricht der Haus-Escherde'r Teiche beobachtet worden und zwar im Frühjahr; nachdem habe ich nie wieder etwas über das Vorkommen dieses Vogels gehört.

113. Grus cinerea. Der Kranich zieht alljährlich zweimal über unser Gebiet hinweg; bisweilen aber lässt sich auch einmal eine kleine Schaar nieder zum Ausruhen. Schöne Tage im October wählen sie zu ihren Herbstzügen und gleiche Tage im April oder frühestens zu Ende März, um in ihre Heimat zurück zu kehren. Alle Züge halten fast genau dieselbe Richtung ein: Von N.O. nach S.W. und umgekehrt.

114. Crex praténsis. Der Wiesenknarrer oder Wachtelkönig gehört zu den ständigen Brutvögeln des Gebietes; er ist jedoch keineswegs häufig. Nasse Wiesen und Getreidefelder in deren Nähe, sowie Kleefelder bilden seinen bevorzugten Wohnort. Im Frühjahr trifft der Wiesenknarrer meist im Anfang Mai oder Ende April ein und begiebt sich im August oder September schon wieder auf die Wanderschaft. Sein Nest steht auf dem Boden im dichten Grase oder Klee und enthält in der zweiten Hälfte des Mai das aus 8-10 Eiern bestehende Gelege; wenn aber in der zweiten Hälfte des Mai noch nicht genügend Deckung für das Nest vorhanden ist, so wird der Bau desselben noch hinausgeschoben.

115. Stagnicola chloropus. Das Teichhuhn ist ständiger Brutvogel im Gebiet; es kommt auf allen stehenden Gewässern vor, welche an den Ufern mit Schilf bewachsen sind und in der Mitte einen offenen Wasserspiegel haben. Wenn auf den von ihnen 
bewohnten Gewässern Stellen im Röhricht vorhanden sind, welche Winters über nicht zufrieren, so hält das Teichhuhn selbst in - strengen Wintern bei uns aus; im andern Falle begiebt es sich im October auf die Wanderschaft und kehrt im Frühjahr bei Eintritt mildern Wetter's zurück. Wenn das Teichhuhn, wie gesagt, irgend sein Auskommen finden kann, so verlässt es uns im Winter nicht; ich habe einst im December an einer solchen frostfreien Stelle im Röchricht 8 Teichhühnchen beobachtet und einzelne, vielleicht das Pärchen des betreffenden Teiches, waren in jedem Winter an jener Stelle anzutreffen. In der zweiten Hälfte des April findet man in dem schwimmenden Neste, welches immer im Röhricht, bald nah, bald entfernter vom Ufer, steht, das volle, aus 7-10 Eiern bestehende Gelege.

116. Fulica atra. Das Blässhuhn berührt unser Gebiet nur auf dem Durchzuge; als Brutvogel kommt es nicht in demselben vor; das einzige Exemplar, welches ich hier gesehen und auch geschossen habe, fand sich in der ersten Woche des December 1882 an der Leine vor.

117. Eine Gänse-Art habe ich aus der Ferne öfter über das Gebiet hinwegziehen und auch, wenn auch selten, sich im Gebiet niederlassen sehen; da ich aber bislang noch habe keinen Vogel erlegen können, so vermag ich auch nicht mit Sicherheit die Art anzugeben.

118. Anas boschas. Die Wildente ist ein ständiger Brutvogel im Gebiet und kommt als solcher hauptsächlich an den durch die Leine-Correction entstandenen alten Wasserarmen vor. Im Winter stellen sich von den Meeresküsten oft sehr grosse Schaaren ein, welche hier überwintern. Die Wildente legt regelmässig ihr Nest in der Nähe des Gewässers an; es sind mir aber auch Fälle bekannt, wo ein Nest über eine Wegestunde von der Leine entfernt gefunden wurde. So z. B. fand ein Forstbeamter einst im Walde eine brütende Wildente auf ihren Eiern; mehrere Male wurde das Nest inspicirt und war einst über Nacht die alte Ente mit sammt dem Inhalt der Eier verschwunden. Die zahlreichen Eierhälften zeigten an, dass die Jungen aus den Eiern geschlüpft waren; aber es war von keiner jungen, noch von der alten Ente etwas zu sehen. Die Alte hat ihre Jungen zweifelsohne zum nächsten Wasser getragen. Eine andere Entenfamilie, eine Alte und 8 Junge, begegneten mir einst, wie sie eben das Nest in einem Kornfelde verlassen hatten und sich anschickten, einen 
in der Näbe liegenden Teich zu erreichen. Da sie höchstens noch 50'Schritt von dem Teiche entfernt waren, nehme ich an, dass sie denselben ungestört erreicht haben; am folgenden Tage war von diesem Teiche, da er schilflos war, die Ente sammt Jungen verschwunden und auf einen andern, eine halbe Stunde davon entfernten sehr schilfreichen Teiche übergesiedelt. Wie diese kleinen höchstens 3 Tage alten jungen Enten diesen Weg zurückgelegt haben weiss ich nicht, glaube aber auch bestimmt, dass sie von der Mutter fortgetragen sind.

Von den übrigen Entenarten habe ich hier constatirt:

119. Anas penelope. Die Pfeifente.

120. A. querquedula. Die Knäkente.

121. Fuligula ferina. Die Tafelente.

Alle drei besuchen uns gelegentlich des Winterzuges, verweilen auch wohl eine Zeit lang hier; sie erscheinen aber sehr unregelmässig und nur selten.

122. Mergus mergansér. Der Gänsesäger.

123. Mergus albellus. Der Zwergsäger.

Beide sind seltene Gäste im Gebiet, die sich zur Winterzeit $a b$ und an einmal hier zeigen.

124. Rissa tridactyla. Die dreizehige Möve wurde vor einigen Jahren im Frühling auf einem Teiche zu Haus-Escherde geschossen; sie gehört jedenfalls zu den seltensten Gästen des Gebietes.

125. Graculus cormoranus. Der Comoran ist von mir einmal im Gebiet beobachtet und auch erlegt worden; auch er besucht unser Gebiet nur äusserst selten; dieses erwähnte Exemplar hielt sich Anfangs November an der Leine auf.

126. Podiceps minor. Der Zwergsteissfuss ist seit einigen Jahren im Gebiet als Brutvogel aufgetreten, so z. B. auf einem Teiche in Haus-Escherde, wo ich das Pärchen den ganzen Sommer über beobachtet habe. Auch im Winter hält der Steissfuss an offenen Gewässern. bei uns aus, zieht die stehenden den fliessenden vor und besucht letztere erst dann, wenn das stehende Gewässer zugefroren ist.

Im Vorstehenden habe ich, so gut es mein Wissen erlaubte, eine Uebersicht derjenigen Arten gegeben, welche das Gebiet mehr oder weniger regelmässig besuchen oder in ihm sesshaft sind. Von den aufgeführten 126 Arten brüten oder haben im Gebiet gebrütet: 
Die Brutvögel u. Gäste der Umgebung Gronau's in Hannover. 399

88 Arten; 6 Arten sind Brüter aus der unmittelbaren Nachbarschaft resp. haben vielleicht auch im Gebiet selbst gebrütet; 32 Arten dagegen sind bis jetzt nur als Gäste zu betrachten. Ich bin überzeugt, die Zahl der letztern ist noch nicht erschöpft und es wird mir im Laufe der Zeit möglich werden, ihre Anzahl noch bedeutend $\mathrm{zu}$ vergrössern.

In dem Vorstehenden habe ich mich der Ausdrücke bedient: „Es ist nicht genau zu bestimmen, ob der und der Vogel im Gebiet gebrütet hat," und in dieser Art mehr. Hierzu möchte ich bemerken, dass dieses in 2 Beobachtungen begründet liegt. Einestheils nämlich habe ich junge Vögel einer Art im Gebiet beobachtet, so dass man zur Annahme berechtigt war, es könnten dieselben in unserm Gebiet ausgebrütet sein.

Andererseits aber war ich auch wiederum in der Lage, ein Pärchen vor, während und nach der Brutzeit an einem bestimmten Orte zu beobachten, so dass man auch hieraus leicht den Schluss ziehen konnte, es habe daselbst gebrütet. Ich habe natürlich von Unmöglichkeiten in dieser Beziehung gänzlich Abstand genommen.

\section{Com pe n d i u $\mathrm{m}$}

\section{der nea beschriebenen Gattungen und Arten.}

\section{Von}

\section{Ant. Reichenow und Herman Schalow.}

(Fortsetzung von Jahrg. 1882 S. 449-461.)

XI. Folge. Serie VII.

Fam. STRUTHIONIDAE.

149. Struthio molybdophanes.

Ant. R ei ch en ow, Sonntagsb. d. Norddeutsch. Allgem. Zeitung No. 37, 16. September 1883.

Dem Struthio camelus L. ähnlich, das Männchen mit schwarzem Gefieder und mit weissen Flügel- und Schwanzfedern, aber dadurch höchst auffallend unterschieden, dass alle nackten Körpertheile, Kopf, Hals und Beine, nicht hellroth wie bei St. camelus, sondern graublau gefärbt sind, während der Schnabel sowie die Horntafeln an der Vorderseite des Laufes durch blass mennigrothe Farbe grell sich abheben.

Hab.: Vermuthlich die Somali- und Galla-Länder.

$$
\text { Fam. PROCELLARIIDAE. }
$$

150. Aeipetes, n. gen.

W. A. Forbes, Zoolog. of the Voyage of H. M. Challenger pt. 9.1882 p. 59. 


\section{$2 \mathrm{BHL}$ Biodiversity Heritage Library}

1883. "Die Brutvögel und Gäste der Umgebung Gronau's in Hannover." Journal fu

r Ornithologie 31, 368-399. https://doi.org/10.1007/bf02001783.

View This Item Online: https://www.biodiversitylibrary.org/item/101690

DOI: https://doi.org/10.1007/bf02001783

Permalink: https://www.biodiversitylibrary.org/partpdf/142169

\section{Holding Institution}

Smithsonian Libraries

\section{Sponsored by}

Biodiversity Heritage Library

\section{Copyright \& Reuse}

Copyright Status: Public domain. The BHL considers that this work is no longer under copyright protection.

This document was created from content at the Biodiversity Heritage Library, the world's largest open access digital library for biodiversity literature and archives. Visit BHL at https://www.biodiversitylibrary.org. 